\title{
Perancangan alat bantu untuk memperbaiki proses perencanaan produksi pada PT X
}

\author{
Hans Gerald Regawa* \\ Program Studi Magister Manajemen, Fakultas Ekonomi dan Bisnis, Universitas Katolik Parahyangan \\ J1. Merdeka 30. Bandung. 40117. Indonesia \\ hans_gerald@hotmail.com \\ *Penulis Korespondensi
}

Submitted: Agt 6, 2018; Reviewed: Agt 14, 2018; Accepted: Sep 21, 2018

\begin{abstract}
Production planning is part of the operational management that is important in a company. By managing production planning properly, the production process in a company will be able to run better. PT X is a company that produces vehicle spareparts for private cars. The company runs make to order system to fulfill the production procss. In the make to order system, a new product will begin to be produced by the company if there is an order from the customer. In this system, a company has inventory i.e. raw material and work in process. The problem are PT X have lack of raw materials and the absence of lead time given by the company to customers about when a product will be sent. To overcome this problem, improvements are made to the existing production planning system. Improvements begin by changing the way raw materials are purchased. This is done by treating the system with order point. With this system, company will never experience a shortage of raw materials because when raw material below order point, company must immediately order new raw materials. Thus the production process will not be disturbed and can run smoothly. In determining when a product will be completed and sent to customers, a production planning system with DSS tools (decision support system) is made using Microsoft Excel tools. By using DSS, the system will automatically display when a product will be finished and when it can be sent to the customer, when to buy raw materials, and how much production order is. Accordingly, the company can provide certainty of information to customers when the products have been produced and shipped.
\end{abstract}

Keywords: decision support system; operation management; order point; production order Abstrak: Perencanaan produksi adalah suatu hal yang penting dalam suatu perusahaan. Dengan
mengatur perencanaan produksi dengan baik, proses produksi dalam suatu perusahaan akan dapat
berjalan dengan lebih baik. PT X adalah suatu perusahaan yang bergerak dalam proses produksi
suku cadang kendaraan bermotor berjenis mobil pribadi. Perusahaan dalam proses produksinya
menganut sistem make to order. Dalam sistem ini, suatu produk baru akan mulai diproduksi oleh
perusahaan jika ada order dari pelanggan. Dalam sistem ini, suatu perusahaan mempunyai
persediaan berupa barang-barang mentah atau setengah jadi. Permasalahan yang selama ini terjadi
pada PT X adalah bahan baku yang kurang dan tidak adanya lead time yang diberikan oleh
perusahaan kepada pelanggan mengenai kapan suatu produk akan dikirim. Untuk mengatasi masalah
ini, perusahaan melakukan perbaikan sistem perencaan produksi yang ada. Perbaikan dimulai
dengan mengubah cara pembelian bahan baku. Hal ini dilakukan dengan memperlakukan sistem
order point. Dengan sistem ini, perusahaan tidak akan pernah mengalami kekurangan bahan baku
karena setiap kali bahan baku di bawah order point, perusahaan harus segera memesan bahan baku
yang baru. Sehingga proses produksi tidak akan terganggu dan bisa berjalan dengan lancar. Untuk
DOI: https://doi.org/10.28932/jmm.v19i1.1003 
menentukan kapan waktu suatu produk akan selesai dibuat dan dikirim ke pelanggan, perusahaan membuat sistem perencanaan produksi dengan alat bantu DSS (decision support system) dengan menggunakan sarana Microsoft Excel. Dengan memakai DSS, operator tinggal mengisi masukan yang diperlukan setelah itu secara otomatis sistem akan menampilkan kapan suatu produk akan selesai diproduksi dan kapan bisa dikirim ke pelanggan, kapan waktu untuk membeli bahan baku, dan berapa banyak production order yang ada. Dengan demikian pihak perusahaan dapat memberikan kepastian informasi kepada pelanggan kapan produk akan selesai diproduksi dan dikirim.

Kata kunci: decision support system; manajemen operasi; order point; production order

\section{PENDAHULUAN}

Manusia selalu membutuhkan sarana transportasi dalam melakukan aktivitasnya seperti pergi ke sekolah, kantor, menuju tempat kerja, menuju ke tempat liburan dan sebagainya. Seiring perkembangan waktu kebutuhan akan transportasi akan semakin banyak. Hal ini terjadi karena jumlah populasi manusia juga semakin banyak. Di Indonesia jumlah kendaran bermotor setiap tahun mengalami pertambahan jumlah baik motor maupun mobil.

Dengan bertambahnya motor dan mobil maka diperlukan juga suku cadang untuk merawat sepeda motor dan mobil tersebut. Bertambahnya waktu akan membuat segala macam keperluan menjadi semakin mahal contohnya gaji pegawai, biaya untuk membeli alat-alat dan mesin keperluan produksi, harga bahan baku, dan hal lain yang berkaitan dengan masalah keuangan akan menjadi semakin meningkat.

Sebuah perusahaan tentunya harus beradaptasi dengan berbagai hal di atas bila ingin tetap bertahan seperti dengan mengirim dan memproduksi lebih banyak lagi hasil produksinya supaya pemasukan perusahaan bertambah daripada sebelumnya. Untuk menghadapi jumlah pesanan yang semakin lama semakin banyak dan menghadapi biaya produksi yang semakin mahal, perusahaan perlu memiliki suatu pengaturan rantai pasokan yang baik. Sebuah proses produksi yang dimulai dari raw materials sampai menjadi final products dan siap dijual kepada distributor atau konsumen akhir (Chopra \& Meindl, 2015).

Salah satu bagian dari supply antara lain seperti production and inventory management (PIM). PIM adalah suatu pengaturan untuk bidang manufaktur dan pendistribusian dari suatu produk (Fogarty, Blackstone, \& Hoffman, 1992). Dengan melakukan pengaturan terhadap sistem produksi dan persediaan, PIM dapat membantu perusahaan untuk menentukan berapa banyak barang yang akan disimpan, berapa banyak barang yang akan diproduksi, berapa lama suatu produk harus selesai dibuat, serta menentukan kapan suatu produk akan dikirim kepada pelanggan. PT X adalah perusahaan yang bergerak dalam bidang memproduksi suku cadang untuk kendaraan bermotor khususnya mobil.

PT X mengunakan sistem make to order dalam melayani semua jenis suku cadang yang diminta oleh konsumen. Produk yang dijual oleh perusahaan beragam antara lain bushing arm atau bos sayap, support shock breaker, engine mounting, dan transmission engine. Area penjualan produk PT X mencakup Jakarta, Bandung, Bekasi, dan Cirebon. Tetapi pasar utama yang dituju oleh PT X adalah Jakarta. Para pelanggan PT X adalah pelaku grosir. Untuk menjaga persaingan dengan para pesaingnya, PT X harus memiliki manajemen yang baik dalam proses produksinya.

Salah satu penerapan manajemen yang baik dalam proses produksi adalah pengelolaan penjadwalan produksi yang baik pada perusahaan. Tujuan penelitian ini adalah menghasilkan suatu penjadwalan produksi yang baik sehingga dapat membantu perencanaan produksi yang berada pada perusahaan. Alat bantu yang digunakan untuk mempermudah operator dalam menentukan penjadwalan produksi adalah penggunaan Decision Support System (DSS).

DSS adalah suatu alat bantu berbasis sistem komputer yang interaktif, serta dapat membuat suatu model dan karakteristik untuk menyelesaikan suatu masalah dan mencari solusinya dalam tahap melakukan proses manajemen (Sharma, Chand, Sharma, \& Yadav, 2015). DSS membantu manajer untuk membuat keputusan yang lebih baik. DSS adalah sebuah sistem yang digunakan untuk mendukung para pembuat keputusan pada tingkat manajerial dalam keputusan semiterstruktur tetapi tidak menggantikan peran mereka (Turban \& Aronson, 2009). 
Alat bantu yang digunakan adalah DSS karena dapat digunakan oleh semua tingkatan manajer mulai dari top manager sampai line manager. Selain itu DSS sangat fleksibel dan juga adaptif terhadap permintaan yang tidak pernah sama, mempercepat proses perhitungan, dapat meningkatkan produktivitas dalam perusahaan, dan meningkatkan kualitas pengambilan keputusan.

\section{METODE}

Metodologi penelitian terdiri dari penentuan topik, studi lapangan, identifikasi serta perumusan masalah, pembatasan dan asumsi, studi literatur, pengumpulan data, pengolahan data, pengaplikasian DSS, analisis, dan simpulan serta saran yang akan diberikan. Berikut adalah bagan dari metodelogi penelitian yang dilakukan ditunjukan pada Gambar 1.

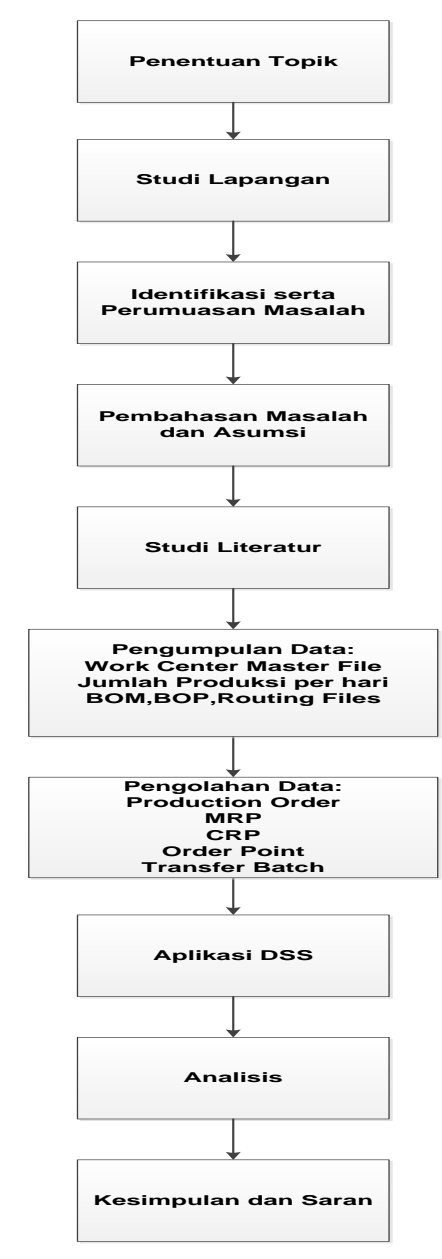

Gambar 1. Metodologi penelitian

\section{HASIL DAN PEMBAHASAN}

3.1 Pengumpulan data work center master file

Pengumpulan data yang pertama dilakukan adalah mengumpulkan semua informasi dan data yang berada pada work center perusahaan. PT X memiliki satu shift kerja. PT X memiliki lima buah lintasan, di mana tiap lintasan terdiri dari tiga mesin proses produksi. Proses produksi pertama pada PT X terdiri dari proses pemberian lem besi pada setiap lempengan besi. Proses yang kedua adalah proses pencetakan karet. Pada proses ini pelat besi yang telah dilem akan dicetak bersama dengan potongan karet gelondongan. Proses produksi terakhir adalah proses pengecatan. PT X memiliki 15 buah mesin. Di mana setiap proses terdiri dari masing-masing lima mesin. Setiap mesin yang berada pada PT X memiliki efisiensi dan utilisasi masing-masing sebesar 95 persen. 
Proses pengeleman memiliki setup time selama 10 menit, proses pencetakan memiliki waktu setup selama 30 menit. Proses pengecatan memiliki waktu setup selama 10 menit. Proses pengeleman pelat besi membutuhkan run time selama tiga menit, proses pengeresan memakan run time selama 15 menit, proses pengecatan memakan run time selama lima menit. Lama waktu kerja yang ditetapkan oleh perusahaan adalah selama 7,5 jam per hari. Tabel berikut menunjukan tabel dari data work center master file.

Tabel 1. Database work center master file

\begin{tabular}{cccccccccc}
\multirow{2}{*}{$\mathrm{P}$} & \multicolumn{2}{c}{ Run Time } & \multicolumn{2}{c}{ Setup Time } & \multirow{2}{*}{ SM } & \multirow{2}{*}{$\mathrm{E}$} & $\mathrm{U}$ & \multirow{2}{*}{ JK } \\
\cline { 2 - 9 } & Menit & Jam & Menit & Jam & & & & & \\
\hline Lem & 3 & 0,05 & 10 & 0,17 & 1 & 5 & $95 \%$ & $95 \%$ & 7,5 \\
Pres & 15 & 0,25 & 30 & 0,50 & 1 & 5 & $95 \%$ & $95 \%$ & 7,5 \\
Cat & 5 & 0,08 & 10 & 0,17 & 1 & 5 & $95 \%$ & $95 \%$ & 7,5 \\
\hline
\end{tabular}

Keterangan:

S: Shift

JM: Jumlah mesin

E: Efisiensi

U: Utilitas

JK: Jam kerja

Sumber: Data pengamatan pada perusahaaan

3.2 Jumlah produksi per hari

Data jumlah produksi per hari diambil dengan tujuan melihat berapa banyak produk yang dapat dihasilkan oleh perusahaan. Dengan melihat data tersebut, perusahaan dapat menentukan kebutuhan material per produk, serta dapat menentukan berapa banyak banyak bahan baku untuk melakukan proses produksi. Setelah itu diambilah jumlah produksi terbesar sebagai acuan. Hal ini ditunjukkan agar tidak ada kekurangan bahan baku pada saat akan membeli bahan baku. Data produksi per hari yang diambil adalah data produksi selama bulan September. Tabel dari jumlah produksi per hari yang dapat dihasilkan oleh PT X ditunjukan Tabel 2.

Tabel 2. Data produksi per hari bulan Oktober 2017

\begin{tabular}{ccccc} 
Tanggal & $\begin{array}{c}\text { Jumlah } \\
\text { Produksi }\end{array}$ & & Tanggal & $\begin{array}{c}\text { Jumlah } \\
\text { Produksi }\end{array}$ \\
\cline { 1 - 2 } \cline { 5 - 5 } 2 & 100 & & 16 & 84 \\
2 & 90 & & 17 & 90 \\
3 & 86 & & 18 & 0 \\
4 & 0 & & 19 & 89 \\
5 & 90 & & 20 & 94 \\
6 & 95 & & 21 & 93 \\
7 & 93 & & 22 & 98 \\
8 & 88 & & 23 & 90 \\
9 & 90 & & 24 & 100 \\
10 & 91 & & 25 & 0 \\
11 & 0 & & 26 & 96 \\
12 & 0 & & 27 & 100 \\
13 & 90 & & 28 & 97 \\
14 & 92 & & 29 & 100 \\
15 & 89 & & 30 & 89 \\
\cline { 5 - 5 } & & & 31 & 90 \\
\cline { 5 - 5 } & & &
\end{tabular}

Sumber: Data perusahaan

\subsection{Bill of material or planning bill of material}

Bill of material (BOM) adalah gambaran tentang produk jadi yang terdiri dari daftar barang atau material yang diperlukan untuk melakukan proses assemble atau untuk memproduksi suatu barang jadi (Arnold, Chapman, \& Clive, 2016). Perencanaan BOM merupakan suatu tabel yang menunjukan 
berbagai komponen yang diperlukan untuk membuat suatu produk jadi. Dalam perencanaan BOM juga ditunjukkan berapa banyaknya komponen yang diperlukan untuk membentuk suatu produk jadi.

Perencanaan BOM yang dimiliki oleh PT X disimpan pada lantai produksi. Hal ini bertujuan agar operator mengetahui komponen apa saja yang diperlukan untuk membuat berbagai produk seperti engine mounting, transmission mounting, support shock breaker, dan bos sayap.

Perencanaan BOM PT X terdiri dari dua tingkat, yaitu tingkat 0 dan 1 . Tingkat 0 berupa produk yang telah selesai diproduksi. Produk-produk tersebut adalah engine mounting (EM), transmission mounting, support shock breaker, serta bos sayap. Tingkat 1 berisi tentang komponen-komponen yang dibutuhkan untuk menghasilkan suatu produk. Komponen-komponen yang dibutuhkan berupa lem besi, pelat besi, karet gelondongan, serta cat.

Kolom tingkat menunjukkan tingkat dari komponen-komponen yang digunakan. Kolom nomor suku cadang menunjukan nomor barang dari komponen yang digunakan. Kolom keterangan menunjukkan keterangan apakah produk merupakan barang jadi atau masih berupa komponen. Kolom 5 menunjukkan satuan setiap komponen yang digunakan. Kolom barang jadi memberikan informasi berupa berapa banyak produk yang dapat dihasilkan atau berapa komponen yang diperlukan untuk memproduksi suatu produk. Contohnya part 1100 merupakan nomor dari produk jadi, part K2101 menunjukkan komponen karet untuk membuat produk bos sayap CRV, part B2201 menunjukkan komponen pelat besi yang digunakan untuk memproduksi bos sayap CRV, part C2300 menunjukkan komponen cat yang digunakan untuk mengecat produk, dan part L2400 merupakan komponen lem yang digunakan pada pelat besi. Untuk menghasilkan satu unit produk bos sayap CRV diperlukan karet sebanyak $0,066 \mathrm{~kg}$, satu unit pelat besi, $0,0192 \mathrm{~kg}$ lem dan $0,0192 \mathrm{~kg}$ cat. Tabel database bill of material atau planning bill of material dipaparkan pada Tabel 3 berikut.

Tabel 3. Data planning bill of material

\begin{tabular}{llccc}
$\begin{array}{l}\text { Nomor Suku } \\
\text { Cadang }\end{array}$ & Nama Komponen & $\begin{array}{c}\text { Quantity for Each } \\
\text { Assembly }\end{array}$ & $\begin{array}{c}\text { Pemakaian Bahan } \\
\text { Baku per Pesanan }\end{array}$ & Satuan \\
\hline 2100 & Pelat Besi & 1 & 100 & $\mathrm{unit}$ \\
2201 & Karet & 0,066 & 7 & $\mathrm{~kg}$ \\
2202 & Karet & 0,125 & 13 & $\mathrm{~kg}$ \\
2203 & Karet & 0,111 & 12 & $\mathrm{~kg}$ \\
2204 & Karet & 0,066 & 7 & $\mathrm{~kg}$ \\
2205 & Karet & 0,125 & 13 & $\mathrm{~kg}$ \\
2206 & Karet & 0,125 & 13 & $\mathrm{~kg}$ \\
2207 & Karet & 0,050 & 5 & $\mathrm{~kg}$ \\
2208 & Karet & 0,111 & 12 & $\mathrm{~kg}$ \\
2209 & Karet & 0,111 & 12 & $\mathrm{~kg}$ \\
2210 & Karet & 0,062 & 7 & $\mathrm{~kg}$ \\
2211 & Karet & 0,090 & 9 & $\mathrm{~kg}$ \\
2212 & Karet & 0,125 & 13 & $\mathrm{~kg}$ \\
2213 & Karet & 0,083 & 9 & $\mathrm{~kg}$ \\
2214 & Karet & 0,111 & 12 & $\mathrm{~kg}$ \\
2215 & Karet & 0,071 & 8 & $\mathrm{~kg}$ \\
2216 & Karet & 0,066 & 7 & $\mathrm{~kg}$ \\
2300 & Cat & 0,019 & 2 & $\mathrm{~kg}$ \\
2400 & Lem & 0,019 & 2 & $\mathrm{~g}$
\end{tabular}

Sumber: Data dari perusahaan

Tabel 4. Keterangan BOM

\begin{tabular}{cl} 
No & Jenis Produk \\
\hline 1 & Bos sayap CRV \\
2 & E/M CRV \\
3 & T/M CRV \\
4 & Bos sayap Jazz \\
5 & E/M Jazz
\end{tabular}




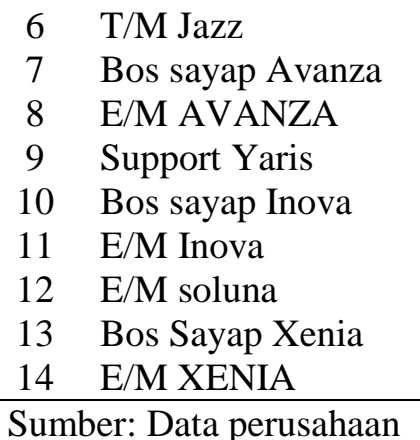

\subsection{Routing files}

Routing files menggambarkan jalur yang direncanakan oleh suatu perusahaan untuk menunjukkan proses urutan produksinya dilangkapi perkiraan waktu tiap operasi (Gaspersz, 2011). Proses produksi dimulai dari proses pengeleman lem besi pada pelat besi. Proses ini dilakukan dengan menggunakan spary gun. Prosesnya lem disemprotkan pada pelat besi yang telah tersedia. Proses pengeleman memakan waktu selama tiga menit per produk. Stasiun pengeleman terdiri dari lima line.

Setelah proses pengeleman, proses selanjutnya adalah mengepres pelat besi tersebut dengan potongan karet gelondongan. Sama dengannya proses pengeleman, proses pengepresan juga terdiri dari lima line dengan masing-masing line memiliki satu mesin. Mesin yang digunakan dalam proses pengepresan adalah press machine. Proses pengepresan memakan waktu sekitar 15 menit.

Tahap akhir dari proses produksi adalah pengecatan yang memakan waktu sekitar lima menit. Proses ini dilakukan dengan memakai spray gun dengan cara menyemprotkan cat pada produk yang telah selesai dipres. Penggunaan flowchart dari proses routing files akan memperjelas proses yang ada. Jumlah batch per proses produksi yang ditentukan perusahaan adalah 100 unit per proses. Waktu batch diperoleh dengan rumus $\mathrm{T}+(\mathrm{B} \times \mathrm{WP})$. Dengan $\mathrm{T}$ adalah waktu setup mesin, B adalah jumlah batch dan WP adalah waktu proses.

Tabel 5. Tabel routing files

\begin{tabular}{lrrr}
\multicolumn{1}{c}{ Keterangan } & \multicolumn{1}{c}{ Lem } & \multicolumn{1}{c}{ Pres } & \multicolumn{1}{c}{ Cat } \\
\hline Waktu proses & 3 & 15 & 5 \\
Waktu batch & 301 & 1.530 & 515 \\
Waktu mulai & 0 & 3 & 18 \\
Mulai batch & 0 & 301 & 1.831 \\
Transfer batch & 300 & 1.500 & 500 \\
\hline \multicolumn{2}{l}{ Sumber: Data pengamatan pada perusahaan }
\end{tabular}

\subsection{Master production scheduling (MPS)}

Pengolahan data dimulai dengan melihat production order dari MPS. MPS adalah pernyataan tentang produk apa yang akan diproduksi, berapa kuantitasnya, dan kapan waktu yang diperlukan untuk menyelesaikan produk tersebut (Arnold, Chapman, \& Clive, 2016). MPS pada penelitian ditunjukan pada Tabel 6.

Tabel 6. Tabel MPS

\begin{tabular}{lllllllllll} 
Bos Sayap CRV & 1 & 2 & 3 & 4 & 5 & 6 & 7 & 8 & 9 & 10 \\
\hline MPS & 100 & & & & & & & & \\
POH & 0 & 0 & 0 & 0 & 0 & 0 & 0 & 0 & 0 & 0 \\
\hline
\end{tabular}

Keterangan: Angka 1,2,3, dan seterusnya merupakan tanggal. Warna merah menandakan hari libur. Sumber: Data perusahaan

\subsection{Material requirement planning (MRP)}

MRP dibuat untuk mengetahui kebutuhan material yang akan digunakan dalam melakukan proses produksi (Arnold, Chapman, \& Clive, 2016). Dengan merancang MRP yang baik, proses produksi perusahaan akan berjalan dengan lancar. Dengan MRP perusahaan juga dapat mengetahui kapan waktu untuk membeli bahan baku jika jumlah persediaan bahan baku yang berada pada gudang telah 
di bawah order point. Berikut akan diberikan contoh MRP pada bos sayap CRV. Lead time dari supplier adalah 12 hari kerja, dengan lot size berjenis fix lot size dengan jumlah 500 buah pelat besi. Jika jumlah planned order release (PORL) lebih kecil dari jumlah order point, maka perusahaan akan membeli bahan baku sejumlah lot size dari pemasok. Jika jumlah yang dipesan masih kurang, maka perusahaan akan memesan dengan jumlah kelipatan dari lot size tersebut. Bahan baku yang dipesan akan sampai sesuai lead time yang ditentukan. Tabel 7 adalah tabel MRP pelat besi bos sayap CRV.

Tabel 7. Tabel MRP pelat besi bos sayap CRV

\begin{tabular}{lrrrrrrrr} 
Bos sayap & 2 & \multicolumn{7}{c}{3} \\
\cline { 2 - 10 } CRV & 14 & 15 & 16 & 17 & 18 & 19 & 20 & 21 \\
\hline $\begin{array}{l}\text { Customer } \\
\text { Order }\end{array}$ & 150 & & & & & & & \\
Allocated & 150 & 0 & 0 & 0 & 0 & 0 & 0 & 0 \\
Available & 200 & 200 & 1200 & 1200 & 1200 & 1200 & 1200 & 1200 \\
PORC & & & 1000 & & & & & \\
PORL & 500 & 500 & 0 & 0 & 0 & 0 & 0 & 0 \\
\hline
\end{tabular}

Keterangan: Angka 1,2,3, dan seterusnya merupakan tanggal. Warna merah menandakan hari libur.

Sumber: Data pengamatan pada perusahaan

\subsection{Capacity requirement planning (CRP)}

CRP memiliki input berupa MRP dalam bentuk PORL dan schedule receipt (SR), data mengenai stasiun kerja serta kapasitas produksi dari setiap stasiun kerja, dan routing file yang merupakan urutan proses suatu komponen beserta dengan waktu run time dan setup time setiap proses (Arnold, Chapman, \& Clive, 2016). CRP dilakukan untuk mengetahui kapasitas setiap mesin yang digunakan dalam proses produksi. Dalam penelitian dilihat kemampuan kapasitas setiap staisun yang terdiri dari stasiun pengelemen, pengepresan, dan pengecatan. Tabel 8 menunjukan CRP pada penelitian.

Tabel 8. Tabel CRP

\begin{tabular}{lcccccc}
\multicolumn{1}{c}{ Periode } & 0 & 1 & 2 & 3 & 4 & 5 \\
\hline Demand & & 0 & 0 & 0 & 0 & 250 \\
Spray gun lem & 0 & 1 & 2 & 3 & 4 & 5 \\
$\begin{array}{l}\text { Cap requirement } \\
\text { Cap available }\end{array}$ & & 0 & 0 & 0 & 0 & 750 \\
$\begin{array}{l}\text { Press machine } \\
\text { Cap requirement }\end{array}$ & 0 & 406,125 & 406,125 & 406,125 & 406,125 & 406,125 \\
& & 0 & 2 & 3 & 4 & 5 \\
Cap available & & 12183,75 & 12183,75 & 12183,75 & 12183,75 & 5 \\
Sparay gun cat & 0 & 1 & 2 & 3 & 4 & 5 \\
Cap requirement & & 0 & 0 & 0 & 0 & 18750 \\
& & & & & & 6091,87 \\
cap available & & 6091,875 & 6091,875 & 6091,875 & 6091,875 & 5 \\
\hline Sur
\end{tabular}

Sumber: Data perusahaan

Cara menghitung CRPnya juga termasuk mudah. Berikut adalah cara yang digunakan untuk menghitung CRP pada PT X. Pertama tentukan dahulu transfer batch yang diinginkan. Penentuan transfer batch ini memakai metode trial and error. Dengan menggunakan metode trial and error, maka ditentukan transfer batch untuk proses lem ke proses pres adalah 100 buah. Sedangkan dari proses pres ke proses lem sebanyak 50 buah. Jika batch pada suatu mesin sudah mencapai batch yang ditentukan, sisanya akan diproduksi menggunakan mesin lain yang berada pada line selanjutnya.

\subsection{Order point dan transfer batch}

Penentuan order point dan proses transfer batch yang tepat adalah hal yang penting dalam proses produksi suatu perusahaan. Dengan menentukan order point dan transfer batch yang tepat, perusahaan tidak akan mengalami kekurangan bahan baku untuk proses produksi. Proses transfer batch yang 
digunakan adalah 100 buah produk per transfer. Dengan sistem order point walaupun persediaan bahan baku di bawah order point sedikit saja, perusahaan akan langsung membeli bahan baku untuk produksi. Untuk menentukan order point, perusahaan membutuhkan data seperti nama komponen, nama produk mobil, pemakaian bahan baku per produk, lead time manufacturing dari setiap jenis produk. Perhitungan order point hanya dilakukan pada pelat besi dan karet karena kedua komponen tersebut mempunyai lead time yang lumayan lama, sedangkan pada komponen lem besi dan cat jika sudah hampir habis dapat langsung membeli pada saat itu juga sehingga tidak terjadi kekurangan bahan baku. Perhitungan order point didapatkan dari rumus berikut.

Keterangan:

$$
P B B=Q \times P M
$$

PBB: pemakaian bahan baku per order

Q: jumlah produksi produk per hari

PM: pemakaian material per order

Tabel 9. Pemakaian bahan baku per order

\begin{tabular}{|c|c|c|c|c|c|c|c|}
\hline No & Nama & Komponen & $\begin{array}{l}\text { Pemakaian } \\
\text { Material } \\
\text { per } \\
\text { Pesanan }\end{array}$ & $\begin{array}{l}\text { Lead time } \\
\quad \text { (hari) }\end{array}$ & $\begin{array}{r}\text { Jumlah } \\
(\mathrm{u}\end{array}$ & $\begin{array}{l}\text { Pesanan } \\
\text { iit) }\end{array}$ & $\begin{array}{c}\text { Allocated } \\
\text { (Unit) }\end{array}$ \\
\hline \multirow[t]{4}{*}{1} & \multirow{4}{*}{$\begin{array}{l}\text { Bos Sayap } \\
\text { CRV }\end{array}$} & Pelat Besi & 1 & 14 & 500 & buah & 100 \\
\hline & & Karet Gelondongan & 0,06666667 & 7 & 100 & $\mathrm{~kg}$ & 7 \\
\hline & & Cat & 0,01923077 & 1 & 10 & $\mathrm{~kg}$ & 2 \\
\hline & & Lem & 0,01923077 & 1 & 8 & $\mathrm{~kg}$ & 2 \\
\hline \multirow[t]{4}{*}{2} & \multirow[t]{4}{*}{ E/M CRV } & Pelat Besi & 1 & 14 & 500 & buah & 100 \\
\hline & & Karet Gelondongan & 0,125 & 7 & 100 & $\mathrm{~kg}$ & 13 \\
\hline & & Cat & 0,01886792 & 1 & 8 & $\mathrm{~kg}$ & 2 \\
\hline & & Lem & 0,01886792 & 1 & 8 & $\mathrm{~kg}$ & 2 \\
\hline \multirow[t]{4}{*}{3} & \multirow[t]{4}{*}{ T/M CRV } & Pelat Besi & 1 & 14 & 500 & buah & 100 \\
\hline & & Karet Gelondongan & 0,11111111 & 7 & 100 & $\mathrm{~kg}$ & 12 \\
\hline & & Cat & 0,01960784 & 1 & 8 & $\mathrm{~kg}$ & 2 \\
\hline & & Lem & 0,01960784 & 1 & 8 & $\mathrm{~kg}$ & 2 \\
\hline \multirow[t]{4}{*}{4} & \multirow{4}{*}{$\begin{array}{l}\text { Bos Sayap } \\
\text { JAZZ }\end{array}$} & Pelat Besi & 1 & 14 & 500 & buah & 100 \\
\hline & & Karet Gelondongan & 0,06666667 & 7 & 100 & $\mathrm{~kg}$ & 7 \\
\hline & & Cat & 0,02 & 1 & 8 & $\mathrm{~kg}$ & 2 \\
\hline & & Lem & 0,02 & 1 & 8 & $\mathrm{~kg}$ & 2 \\
\hline \multirow[t]{4}{*}{5} & \multirow[t]{4}{*}{ E/M JAZZ } & Pelat Besi & 1 & 14 & 500 & buah & 100 \\
\hline & & Karet Gelondongan & 0,125 & 7 & 100 & $\mathrm{~kg}$ & 13 \\
\hline & & Cat & 0,01851852 & 1 & 8 & $\mathrm{~kg}$ & 2 \\
\hline & & Lem & 0,01851852 & 1 & 8 & $\mathrm{~kg}$ & 2 \\
\hline \multirow[t]{4}{*}{6} & \multirow[t]{4}{*}{ T/M JAZZ } & Pelat Besi & 1 & 14 & 500 & buah & 100 \\
\hline & & Karet Gelondongan & 0,125 & 7 & 100 & $\mathrm{~kg}$ & 13 \\
\hline & & Cat & 0,01886792 & 1 & 8 & $\mathrm{~kg}$ & 2 \\
\hline & & Lem & 0,01886792 & 1 & 8 & $\mathrm{~kg}$ & 2 \\
\hline
\end{tabular}

Sumber: Data perusahaan 
Tabel 10. Order point

\begin{tabular}{clccc} 
Nama Komponen & $\begin{array}{c}\text { Nama Produk } \\
\text { Mobil }\end{array}$ & $\begin{array}{c}\text { Pemakaian Bahan } \\
\text { Baku per Produk }\end{array}$ & $\begin{array}{c}\text { Lead Time } \\
\text { Manufacturing }\end{array}$ & Order Point \\
\hline \multirow{5}{*}{ Pelat Besi } & Honda & 100 & 12 & 1.200 \\
& Toyota & 100 & 12 & 1.200 \\
& Daihatsu & 100 & 12 & 1.200 \\
& Carry & 100 & 10 & 1.000 \\
& Timor & 100 & 10 & 1.000 \\
& Honda & 13 & 5 & 65 \\
& Toyota & 13 & 5 & 65 \\
& Daihatsu & 13 & 5 & 65 \\
& Carry & 13 & 5 & 65 \\
\hline
\end{tabular}

Sumber: Data perusahaan

3.9 Decision support system

Untuk memperbaiki sistem proses produksi pada PT X, digunakanlah alat bantu decision support system atau biasa dikenal dengan nama DSS. Sebelum memulai perancangan DSS, pertama dibuat dulu sebuah flow chart dari proses produksi yang akan dirancang. Flow chart dibuat agar DSS yang dibuat menjadi lebih terstruktur dengan baik dan tujuan yang diinginkan tercapai. Gambar 2 adalah flowchart dari proses produksi yang dibuat.

Dalam flow chart ditunjukkan alur dari DSS yang dibuat, pertama pesanan yang masuk ke perusahaan. Setelah menerima jumlah pesanan, pihak perusahaan akan mengecek bagian shop floor. Beban kerja pada shop floor apakah mesin yang tersedia saat ini tersedia atau tidak untuk melakukan proses produksi. Jika mesin tersedia, maka proses produksi akan dimulai. Jika tidak, maka perusahaan menunggu mesin mana yang tersedia baru proses produksi dimulai.

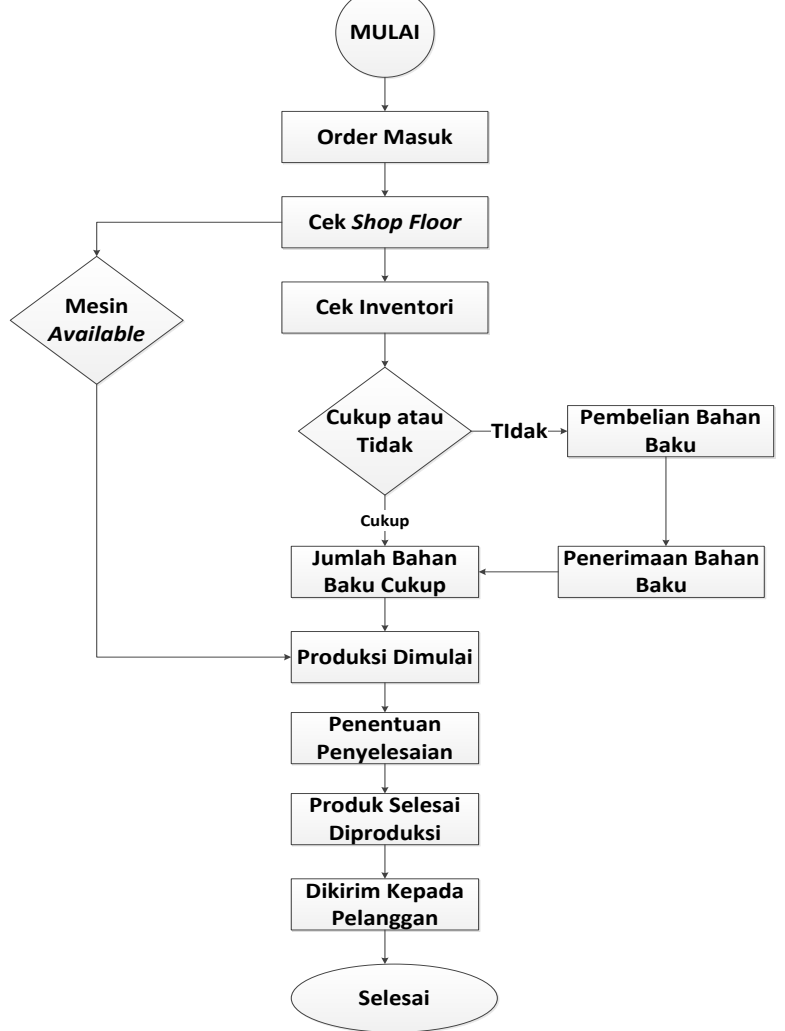

Gambar 2. Flow chart proses produksi

Sumber: Dokumen perusahaan

Dalam proses pembuatan DSS terdapat input, database, model base, process, output, dan user interface. DSS yang dirancang memiliki tiga buah input yaitu shop calendar, customer list, serta 
customer order. Shop calendar yang dibuat sama dengan kalender biasa dimana memuat kapan hari libur dan kapan hari kerja. Customer list adalah daftar nama dari para pelanggan PT X. Sedangkan customer order berisi berbagai produk yang dijual oleh perusahaan. Pengisian input relative sangat mudah karena operator hanya perlu menuliskan nama-nama dari pelanggan yang melakukan pemesanan. Setelah itu nama yang telah diinput tadi akan otomatis terinput juga dalam input customer order. Dalam input customer order, operator selanjutnya memilih jenis produk yang dibeli pelanggan, jumlah pesannya, serta tanggal dan jam pesan dari pelanggan.

Setelah pengisian input tersebut, otomatis nama pelanggan akan masuk ke database perusahaan. Database yang dirancang terdiri dari work center master file, customer list, customer order, jumlah produksi per hari, BOM, dan routing files. Database ini murni berisi data yang akan digunakan dalam melakukan tahap proses dalam DSS. Seperti yang telah disebutkan di atas, DSS juga terdiri dari model base. Dalam model base akan dilakukan penghitungan dari production order, MRP, orderpoint dan transfer batch yang digunakan. Dalam tahap proses DSS yang dirancang terdiri dari MRP dan transfer batch. MRP ini nantinya akan berhubungan dengan production order serta perencanaan pembelian bahan baku. Output dari DSS yang dihasilkan adalah jadwal pemesanan material, jadwal produk selesai diproduksi, dan production order yang akan diberikan kepada lini produksi. Dalam DSS juga terdapat user interface. User interface ini digunakan agar operator dapat melihat hasilnya dan dapat melakukan analisis serta menentukan langkah apa yang harus dilakukan selanjutnya. Operator selanjutnya dapat memberikan feedback kepada sistem atau dapat juga mengubah input baik itu berupa jumlah pesanan, jenis pesanan, dan juga hari kerja yang ada pada shop calendar. Model dari DSS yang dibuat akan ditunjukan pada Gambar 3 berikut.

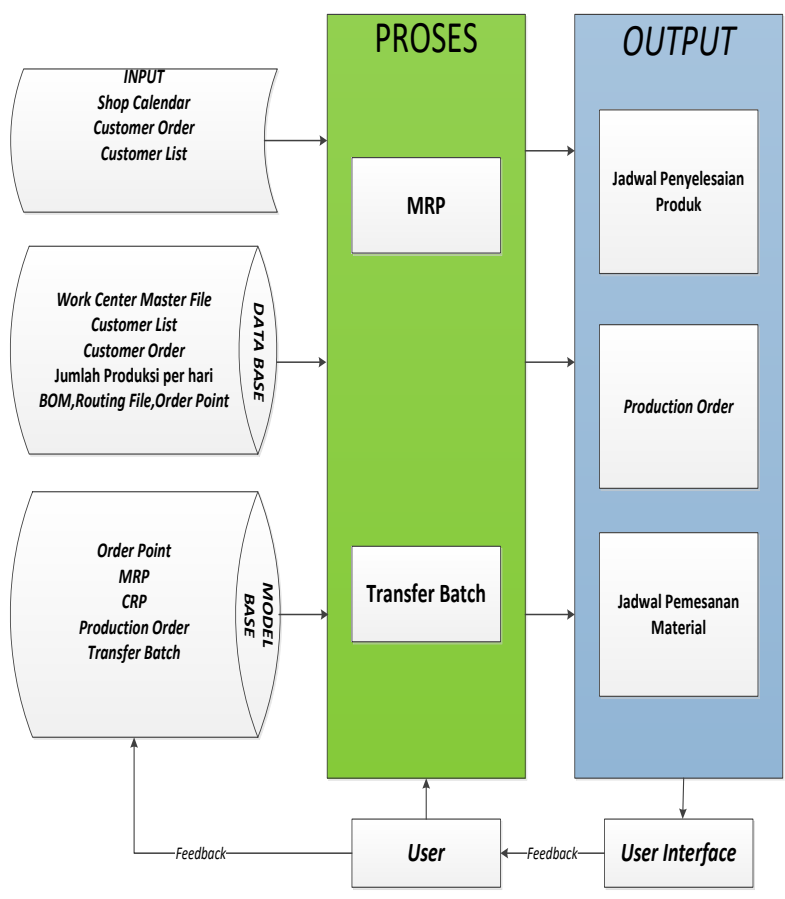

Gambar 3. Model DSS

Sumber: DSS yang dibuat

\subsection{Decision support system input}

Input yang dibuat terdiri dari tiga yaitu shop calendar, customer list, customer order. DSS yang dibuat dalam bentuk tabel. Pengisian input nya mudah, operator hanya tinggal megisinya seperti mengisi Microsoft Excel pada umumnya.

Shop calendar digunakan oleh operator untuk menentukan hari dan tanggal pengiriman produk kepada pelanggan. Jika tanggal kirim jatuh pada hari libur, maka operator dapat menambahkan waktu pengiriman dari produk yang telah selesai tersebut. Selain itu, shop calendar juga dapat digunakan untuk menentukan kapan proses produksi bisa dimulai setelah melihat persediaan. 
Untuk pengisiannya operator hanya perlu memasukan input nama pelanggan ke tabel customer list. Setelah selesai operator memilih option 'submit'. Berikut adalah cara pengisian input dari customer list.

\begin{tabular}{|l|l|}
\hline NAMA & \\
PELANGGAN & TRISTAR \\
\hline ALAMAT & JAKARTA \\
\hline NO TLP & $(021) 657893$ \\
\hline \multicolumn{2}{|c|}{ SUEM T T } \\
\hline
\end{tabular}

Gambar 4. Tabel Input customer list

Sumber: Progam yang dibuat

Setelah mengisi tabel customer list, operator akan mengisi input pada customer order. Cara pengisiannya sama dengan cara pengisian pada input customer list. Berikut adalah cara pengisian dari customer order.

\begin{tabular}{|l|l|}
\hline NAMA & \\
PELANGGAN & TRISTAR \\
\hline JUMLAH & 150 \\
PESANAN & 150 \\
\hline & E/M \\
JENIS ORDER & JAZZ \\
\hline TANGGAL \& & $1 / 9 / 2017$ \\
JAM PESAN & $8: 00$ \\
\multicolumn{2}{|c|}{ SUBMIT } \\
\hline
\end{tabular}

Gambar 5. Tabel Input customer order

Sumber: Progam yang dibuat

\subsection{User interface output pada decision support system}

Dalam DSS yang dirancang terdapat tiga buah output yaitu production order, perencanaan pembelian bahan baku, dan jadwal penyelesaian produk jadi. Berikut dijelaskan output dari DSS yang dirancang.

1. Perencanaan pembelian bahan baku.

Berdasarkan perhitungan yang dilakukan oleh bagian MRP, dapat terlihat jumlah pesanan merupakan input yang berasal dari kolom input customer order. Pesanan yang masuk pada MRP akan dihitung untuk mengetahui apakah perusahaan memiliki cukup bahan baku atau tidak. Jika bahan baku yang dimiliki cukup, maka perusahaan dapat melanjutkan proses produksi. Tetapi jika bahan baku yang dimiliki oleh perusahaan tidak cukup, maka perusahaan harus membeli bahan baku yang dibutuhkan. Dalam tabel berikut terlihat bahwa order masuk tanggal 9, order masih dapat diproduksi karena bahan baku masih mencukupi. Jika jumlah inventori sudah dibawah order point, perusahaan harus memesan jumlah bahan baku sejumlah lot size yang ditentukan oleh pemasok. Karena lot size yang digunakan adalah fixed loot size (FLS), maka jika jumlah pesan tidak mencukup inventori maka harus memesan dengan jumlah kelipatannya.

Contohnya dapat dilihat pada tabel berikut. 
Jurnal Manajemen Maranatha a Vol. 19 Nomor 1, November (2019)

Tabel 11. User interface pembelian bahan baku

Sub Tabel User Interface Pembelian Bahan Baku

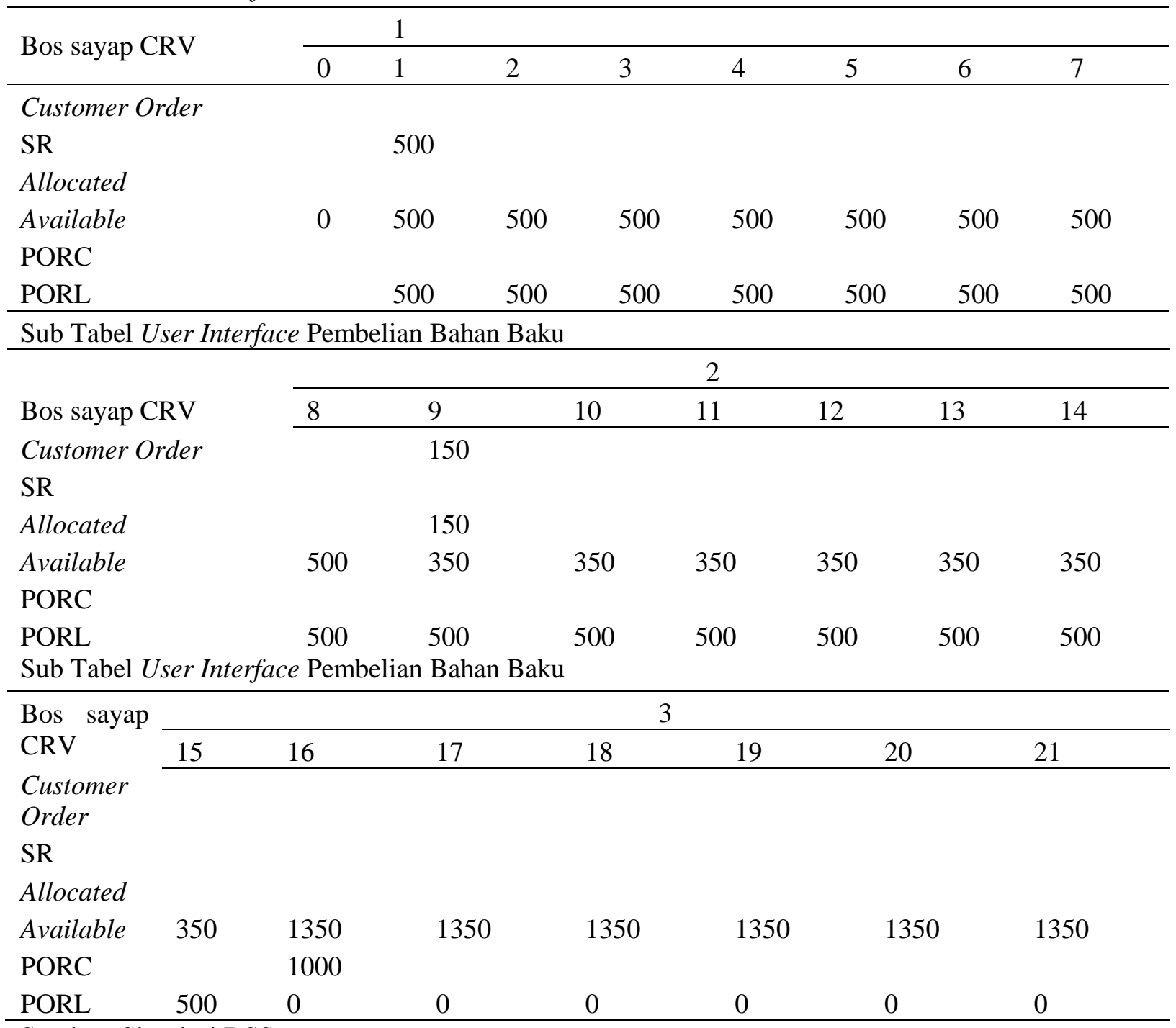

Sumber: Simulasi DSS

\section{Production Order}

Output selanjutnya adalah production order, input yang masuk ke kolom production order adalah input yang diisi oleh operator pada tabel customer order. Hasil dari production order ini akan diberikan oleh manajemen ke pihak operator di lantai produksi. Berikut adalah tabel dari production order.

Tabel 12. User interface production order

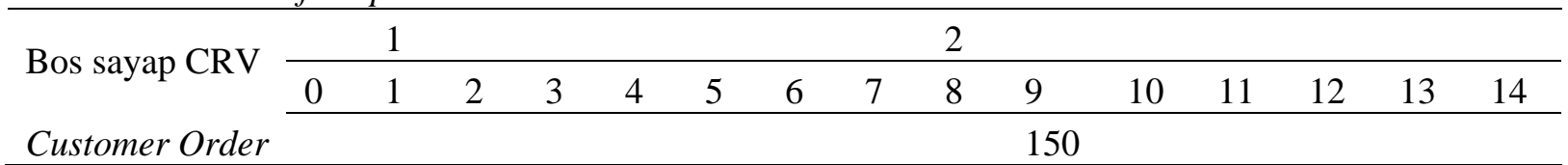

Sumber: Simulasi DSS

3. Jadwal Penyelesaian Produk

Output ketiga adalah jadwal penyelesaian produk. Output ini memungkinkan perusahaan untuk memberikan janji kepada pelanggan kapan akan mulai mengirim produk. Dengan begitu tidak akan ada lagi produk yang terlambat dikirim kepada pelanggan. 
Tabel 13. User interface jadwal penyelesaian produk

\begin{tabular}{|c|c|c|c|c|c|}
\hline $\begin{array}{l}\text { Nama } \\
\text { pelanggan }\end{array}$ & Jenis order & $\begin{array}{l}\text { Jumlah } \\
\text { pesanan } \\
\text { (unit) }\end{array}$ & $\begin{array}{l}\text { Tanggal dan } \\
\text { jam pesan }\end{array}$ & $\begin{array}{l}\text { Tanggal dan jam } \\
\text { penyelesaian }\end{array}$ & $\begin{array}{l}\text { Tanggal dan } \\
\text { jam kirim }\end{array}$ \\
\hline $\begin{array}{l}\text { Trimukti } \\
\text { Intan }\end{array}$ & $\begin{array}{l}\text { Bos sayap } \\
\text { CRV }\end{array}$ & 150 & $\begin{array}{l}01 / 09 / 2017 \\
10: 00 \\
01 / 16 / 2017\end{array}$ & 01/14/2017 9:50 & $1 / 16 / 20179: 50$ \\
\hline Motor & E/M CRV & 200 & $10: 00$ & 01/21/2017 9:50 & $1 / 23 / 20179: 50$ \\
\hline
\end{tabular}

Sumber: Simulasi DSS

\subsection{Decision support system manual}

Bagian ini akan menjelaskan bagaimana cara menggunakan DSS yang dirancang. Panduan manual ini diberikan agar operator mengerti cara mengoperasikan DSS.

1. Buka folder dengan judul Perencanaan Produksi.

2. Jika ada order buka folder input customer list. Isi tabel tersebut lalu pilih option submit.

3. Setelah mengisi input customer list, isilah input pada customer order. Setelah itu pilih option submit.

4. Setelah selesai mengisi input, data nama customer tersebut akan masuk ke data base customer list.

5. Output yang berisis data jumlah order akan masuk ke tabel MRP dan masuk ke tabel production order.

6. Pada tabel MRP akan terlihat apakah bahan baku yang dimiliki perusahaan cukup untuk melakukan proses produksi atau tidak.

7. Output jadwal penyelesaian produksi akan muncul pada sheet output.

8. Pada output tanggal selesai produk dan tanggal kirim produk, operator harus melihat shop calendar perusahaan. Jika tanggal tersebut jatuh pada tanggal merah atau hari libur, operator bisa menambahkan tanggal selesai produk dan tanggal kirim sehari setelah hari libur tersebut.

9. Tahap terakhir operator memasukkan semua hasil yang telah dimasukan.

\section{SIMPULAN DAN SARAN}

Dari hasil dan penelitian dapat diambil simpulan perusahaan mengalami kemajuan setelah mengaplikasikan DSS ke dalam manajemen operasionalnya. Sesuai dengan yang dikemukakan oleh para ahli bahwa DSS akan membantu para manajer untuk mengambil keputusan yang lebih baik. Pengambilan keputusan yang lebih baik terlihat saat ini perusahaan dapat memberikan kepastian kepada para konsumen kapan produksi barang selesai dan kapan barang akan mulai dikirim kepada konsumen.

Saran yang diberikan kepada perusahaan adalah sebagai berikut.

1. Perusahaan menggunakan usulan perbaikan yang sudah diberikan. Karena usulan ini dapat mengatasi permasalahan pada perusahaan seperti mengatasi kekurangan bahan baku dan permasalahan tentang waktu kapan suatu produk selesai diproduksi dan mulai dikirim kepada pelanggan.

2. Dapat digunakan untuk bidang produksi lainnya. Karena proses produksi yang menghasilkan produk apapun tetap merupakan bagian dari manajemen operasional.

3. Dalam penelitian selanjutnya dapat memperhitungkan faktor biaya yang diperlukan.

\section{ACKNOWLEDGEMENTS}

Puji syukur kepada Tuhan Yang Esa atas berkat dan rahmat-Nya kepada penulis selama menyusun jurnal ini. Selain itu penulis juga mengucapkan terima kasih kepada pihak perusahaan atas kesediaannya dalam memberikan tempat dan waktu selama dilakukan proses penelitian. 


\section{REFERENSI}

Arnold, J. T., Chapman, S. N., \& Clive, a. L. (2016). Introduction To Materials Management. New Jersey: Upper Sadle River.

Chopra, S., \& Meindl, P. (2015). Supply Chain Management: Strategy, Planning, and Operation, 6th ed. New Jersey: Pearson Education.

Fogarty, D., Blackstone, J., \& Hoffman, T. (1992). Production and Inventory Management. South Western: Prentice Hall.

Gaspersz, V. (2011). Lean Six Sigma for Manufacturing and Service Industries. Bogor: Vinchristo Publication.

Sharma, R., Chand, N., Sharma, V., \& Yadav, D. (2015). Decision Support System For Operation, Scheduling and Optimization Of Hydro Power Plant In Jammu and Khasmir Region. Journal of Energy Renewable and Sustainable Energy, Vol 43, 1099-1113.

Turban, E., \& Aronson, J. E. (2009). Decision Support System And Intelligent System (7 th ed ed.). New Jersey: Prentice Hall International. 